Z. Klin. Chem. Klin. Biochem.

13. Jg. 1975 , S. $407-412$

\title{
Die mikroanalytische, selektive Bestimmung der unveresterten langkettigen Fettsäuren im Serum ${ }^{1}$ )
}

\author{
Von $A$. Grünert
}

Aus dem Institut für Physiologische Chemie II (Prof. Dr. K. H. Bäßler) der Johannes Gutenberg-Universität Mainz

(Eingegangen am 11. Dezember 1974/15. Mai 1975)

Zusammenfassung: Unter Verwendung eines für die gaschromatographische Bestimmung von Fettsäuren neuen Veresterungsverfahrens mit Alkyljodid über festem Kaliumcarbonat wird ein mikroanalytisches Bestimmungsverfahren zur selektiven, direkten Messung der in niedriger Konzentration im Serum vorliegenden unveresterten Fettsäuren mitgeteilt. Das Verfahren wurde entwickelt, um die aus dem Fettgewebe zur Energieversorgung des Körpers mobilisierten Fettsäuren sowohl in qualitativer, als auch quantitativer Hinsicht bei definierten Versorgungszuständen des Körpers zu erfassen.

\section{Micro method for the selective assay of unesterified long chain fatty acids in serum}

Summary: A microanalytical method is reported for the selective and direct determination of low concentrations of unesterified fatty acids in serum. A new procedure is used to form derivatives of the fatty acids with alkyl iodide, which are separated over a solid phase of $\mathrm{K}_{2} \mathrm{CO}_{3}$. The assay was developed for the qualitative and quantitative determination of unesterified fatty acids mobilized from fat tissue in defined metabolic states.

\section{Einführung}

Eine zentrale Stellung im Fettstoffwechsel nehmen die im Serum an Albumin gebundenen, unveresterten, langkettigen Fettsäuren ein. Ähnliche Bedeutung und Funktion, wie sie die Glucose im Kohlenhydratstoffwechsel aufweist, kommt diesen unveresterten Fettsäuren im Fettstoffwechsel zu. Die analytische Chemie dieser Fettsäuren zeigt in ganz besonderer Weise die Bedeutung allgemein-analytischer Prinzipien beim Umgang mit biologischem Material, wie z. B. Probennahme, Normalwertprobleme, biologische Streubreiten usw. Die Untersuchung der sehr empfindlichen Lipidfraktion der unveresterten Fettsäuren gewährt erst bei Beachtung dieser grundlegenden Voraussetzungen tiefergehende Einblicke in die physiologische Situation des gesamten Stoffwechsels. Auch hinsichtlich zu untersuchender Regelvorgänge - periphere und zentrale Mechanismen - haben die sehr empfindlich reagierenden Fettsäuren aufgrund der hohen Umsatzrate und der dabei vorliegenden, niedrigen Konzentration neben dem speziellen Aspekt für den Fettstoffwechsel allgemeine, grundsätzliche Bedeutung.

Zur analytischen Chemie der Fettsäuren ist zwar bisher eine umfangreiche Literatur vorhanden, die aber über die analytische Problematik nicht hinwegtäuschen kann.

\footnotetext{
1) Die Untersuchungen wurden mit Unterstützung durch die Jacques Pfrimmer-Gedächtnisstiftung und den Fond der Chemischen Industrie durchgeführt.
}

Von den im wesentlichen vier Bestimmungsprinzipien für Fettsäuren in biologischem Material:

1. gravimetrische Verfahren $(1,2)$

2. acidimetrische Titrationsverfahren (3-8)

3. indirekte photometrische Verfahren über Schwermetallseifen (9-14)

4. gaschromatographische Verfahren über die Säureester (15-23)

betrifft der überwiegende Anteil der dazu vorhandenen Arbeiten in der Literatur das indirekte photometrische Verfahren. Gerade dieses Verfahren, welches nicht zu standardisierende Fehlerquellen prinzipieller Natur beinhaltet, über deren Untersuchung und Charakterisierung an anderer Stelle detailliert berichtet wird, kann zu Fehldeutungen fuihren und mißt auch generell dem Aussagewert einer Gesamt-Fettsäurenbestimmung einen falschen Stellenwert zu. Aufgrund vorliegender Untersuchungen soll im Rahmen unseres Forschungsprogramms dieser Stellenwert charakterisiert und der Aussagewert einer Fettsäurenanalyse für die Diagnostik zur Beurteilung der Stoffwechselsituation definiert werden. $\mathrm{Zu}$ diesem Zweck wird eine genaue Arbeitsanleitung für ein neues Bestimmungsverfahren zur selektiven Bestimmung der freien Fettsäuren mitgeteilt, welches im Prinzip vor längerer Zeit an anderer Stelle bekannt gegeben wurde (24). Diese Methode wird in etwas modifizierter Weise seit über $2 \mathrm{Jahren}$ angewandt und hat sich an mehr als 500 Proben bewährt. 


\section{Material und Methoden}

Prinzip

Nach saurer Extraktion der Lipide des Serums in ChloroformMethanol und Eindampfen des Lösungsmittels erfolgt èine selektive, weder zu Umesterungen vorhandener Fettsäureester noch $\mathrm{za}$ Isomerisierungen führende Veresterung der Fettsäuren zu Methylestern nach folgender Reaktionsgleichung:

$\mathrm{R}-\mathrm{COOH}+\mathrm{CH}_{3} \mathrm{~J} \frac{90^{\circ} \mathrm{C}}{\left(\mathrm{K}_{2} \mathrm{CO}_{3}\right)} \mathrm{R}-\mathrm{COOCH}_{3}+(\mathrm{HJ})$

Zur Herstellung verschiedener Ester können beliebige Alkyljodide eingesetzt werden.

\section{Reagenzien}

Extraktionslösung: $13,5 \mathrm{mg}$ Heptadecansäure werden in einem 1 1-Meßkolben in Chloroform-Methanol (Volumina, $200 \mathrm{ml}+$ $100 \mathrm{ml}$ zu 11 Lösung aufgelöst.

Der Titer der $\mathrm{C}_{17}$-Lösung wird von Zeit zu Zeit titrimetrisch mit $0,25 \mathrm{~mol} / \mathrm{l} \mathrm{NaOH}$ aus einer Mikrobürette gegen Nilblau $(0,02 \mathrm{~g} / \mathrm{l}$ in Äthanol) überprüft.

$0,5 \mathrm{~mol} / 1 \mathrm{H}_{2} \mathrm{SO}_{4}$ und $\mathrm{K}_{2} \mathrm{CO}_{3}$ sind handelsüblich (Merck, Darmstadt). Ubertragungslösung ist auch Chloroform-Methanol (Volumina, $200 \mathrm{ml}+100 \mathrm{ml}$ )

\section{Geräte und Apparaturen}

Die Extraktion der Fettsäuren aus dem Serum erfolgt in besonderen Gläsern mit NS 14,5-Glasschliffstopfen (Abb. 1).

Die Volumenreduktion erfolgt in $1 \mathrm{ml}-G$ lasschliff-Gläsern mit NS 14,5 (Abb. 2).

Die Veresterungsreaktion erfolgt in kleinen mit NS 5-Polyäthylenstopfen und Schraubenfedern verschlossenen Glasgefäßen (Abb. 3).

\section{Abb. 1. Extraktionsgefäß}

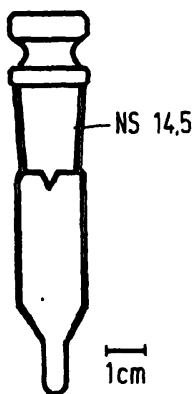

\section{Abb. 2. Eindampfgefäß}

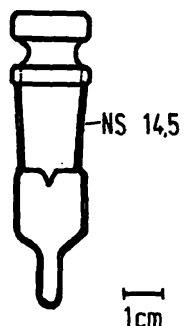

Abb. 3. Reaktionsgefäß

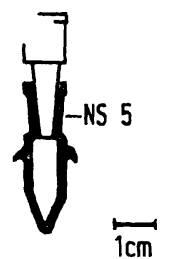

\section{Gaschromatographie}

Perkin-Elmer, PE-900, Zweikanalgerät, ausgestattet mit Glassäulen (150 $\mathrm{cm}$ lang, $2 \mathrm{~mm} \phi_{\mathfrak{i}}$ ) und FID.

Säulenmaterial: Chromosorb WAW, 80-100 mesh, mit 10\% DEGS. Isothermer Betrieb mit $240^{\circ} \mathrm{C}$ im Verdampfungsrohr, $190^{\circ} \mathrm{C}$ im Säulenraum und $270^{\circ} \mathrm{C}$ am Detektor.

Trägergas: $\mathrm{N}_{2} \mathrm{mit} 30 \mathrm{ml} / \mathrm{min}$

Probenvolumen $1,0 \mu l$

Arbeitsvorschrift

$\cdot 1$

\section{Probennahme}

Beim nüchternen Patienten werden im Rahmen der übrigen klinisch-chemischen Untersuchungen zwischen 8.00 und 9.00. Uhr 1-2 ml Nativblut über eine Venenpunktion gewonnen. Das Blut wird in Glasgefäßen aufgefangen und bleibt eine Stunde bei Raumtemperatur stehen. Das nach dem Zentrifugieren überstehende Serum wird vorsichtig abgehebert und in einem zweiten Reagenzglas mit Glasschliffstopfen durch Schütteln homogenisiert. Daß dieser Homogenisierungsschritt für die späteren Analysenergebnisse von Wichtigkeit ist, geht aus den Ergebnissen und der anschließenden Diskussion hervor.

\section{Extraktion}

In den mit Glasschliffstopfen (NS 14.5) verschließbaren Extraktionsgefäßen werden $100 \mu$ Serum vorgelegt und mit $20 \mu \mathrm{l}$ $0,5 \mathrm{~mol} / 1 \mathrm{H}_{2} \mathrm{SO}_{4}$ vermischt.

Aus einer $2 \mathrm{ml}$-Mikrobürette werden genau $1,4 \mathrm{ml}$ organisches Extraktionsmittel zugefügt. Die Gefäße werden verschlossen bis zur Weiterverarbeitung am nächsten Tag bei $4{ }^{\circ} \mathrm{C}$ aufbewahrt. Am nächsten Tag werden die Proben nach kurzem Aufschütteln von Hand bei 3000 Umdrehungen pro Minute in einer Laborzentrifuge zentrifugiert. Dabei floatet das denaturierte Protein mit dem wäßrigen Anteil an die Oberfläche. Mit einer $1000 \mu$ Hamilton-Mikrospritze, mit gasdichtem Teflonstempel und Edelstahlkanüle, wird die Proteinschicht vorsichtig durchstochen und aus dem organischen Unterstand genau $1000 \mu l$ organischer Lösung aspiriert.

Die organische Lösung wird in einem Glasgefäß (Abb. 2) am Rotationsverdampfer im Wasserstrahlpumpenvakuum zur Trockene gebracht. Mit 4 mal $50 \mu l$ Chloroform-Methanol (Volumina $200 \mathrm{ml}+100 \mathrm{ml}$ ) wird der Trockenrückstand in ein Reaktionsgefäß (Abb. 3) überführt. Die Lösung wird erneut am Rotationsverdampfer im Wasserstrahlpumpenvakuum żur Trockne gebracht.

\section{Darstellung der Methylester der Fettsäuren nach einem neuen Veresterungsverfahren}

Die Veresterung im verschlossenen Reaktionskölbchen (Polyäthylen-Stopfen mit NS 5-Schliff, und an Haken befestigten Stahlfedern) erfolgt nach Zugabe von 5-10 mg (Mikrospatelspitze) bei $120^{\circ} \mathrm{C}$ getrocknetem Kaliumcarbonat mit $25 \mu \mathrm{l}$ Methyljodid gelöst in $25 \mu \mathrm{l}$ Essigsäureäthylester.

Nach Zugabe von $\mathbf{5 0} \mu \mathrm{l}$ dieses Reagenzes wird das Kölbchen durch Drehen des Stopfens und Befestigen der Federschrauben gasdicht verschlossen. Die Reaktion erfolgt bei $90^{\circ} \mathrm{C}$ in einem Luftheizbad. Reaktionszeit beträgt 1 Stunde.

\section{Gaschromatographische Bestimmung}

Nach Abkühlen der Proben erfolgt die gaschromatographische Bestimmung durch direkte Injektion von $1 \mu l$ der Reaktionslösung. Die gaschromatographische Trennung erfolgt in Glassäulen an Chromosorb WAW, 80-100 mesh, welches mit 10\% DEGS beschichtet ist.

\section{Auswertung}

Die Auswertung erfolgt über Vergleich der Peak-Flächen. Als innerer Standard wird vom Extraktionsschritt an Heptadecansäure in bekannter Konzentration mitgefuhrt. Über die bekannte Konzentration des inneren Standards und der zugehörigen PeakFläche kann über folgende Formel direkt auf die vorliegende Konzentration jeder einzelnen Säure im Serum $c_{i}$ umgerechnet werden. 


$$
c_{i}(m m o l / l)=\frac{135 \cdot x_{i} \cdot y_{i} \cdot F}{x_{17} \cdot y_{17} \cdot M G_{i}}
$$

$\mathbf{x}_{\mathbf{i}} \mathbf{y}_{\mathbf{i}} \quad$ Gaschromatographische Kenngrößen der Peakflächenberechnung der Fettsäure i

$\mathbf{x}_{\mathbf{i}}=$ korrigierte Retentionszeit $(\mathrm{cm})$

$y_{i}=$ Peakhöhe $(\mathrm{cm})$

$\mathrm{x}_{17} \mathrm{y}_{17}$ Gaschromatographische Kenngrößen des $\mathrm{C}_{17}$-Peaks

$\mathrm{MG}_{\mathbf{i}} \quad$ Molekulargewicht der Fettsäure i

F Verdünnungsfaktor $=1,4$

\section{Ergebnisse}

\section{Probennahme}

Da die Fettsäuren an Eiweiß gebunden sind, macht sich die Präparationsweise der Analysenprobe deutlich im Ergebnis bemerkbar.

In Tabelle 1 und 2 werden die Ergebnisse zweier Untersuchungsreihen gegenübergestellt, bei denen in der ersten

Tab. 1. Parallelbestimmungen aus Serum ohne Homogenisation $(\mathrm{mmol} / \mathrm{l})$

\begin{tabular}{cccccccc}
\hline Probe $C_{14}$ & $C_{16}$ & $C_{16: 1}$ & $C_{18}$ & $C_{18: 1}$ & $C_{18: 2}$ & Summe \\
\hline 1 & 0,011 & 0,265 & 0,034 & 0,125 & 0,337 & 0,141 & 0,913 \\
2 & 0,012 & 0,331 & 0,041 & 0,167 & 0,371 & 0,204 & 1,126 \\
3 & 0,015 & 0,401 & 0,035 & 0,211 & 0,422 & 0,220 & 1,304 \\
4 & 0,013 & 0,276 & 0,034 & 0,121 & 0,343 & 0,143 & 0,930 \\
5 & 0,012 & 0,296 & 0,027 & 0,134 & 0,353 & 0,156 & 0,966 \\
6 & 0,015 & 0,327 & 0,033 & 0,149 & 0,381 & 0,189 & 1,094 \\
7 & 0,013 & 0,300 & 0,036 & 0,151 & 0,347 & 0,167 & 1,014 \\
8 & 0,011 & 0,398 & 0,026 & 0,178 & 0,397 & 0,215 & 1,214 \\
9 & 0,013 & 0,221 & 0,029 & 0,100 & 0,303 & 0,119 & 0,785 \\
10 & 0,012 & 0,285 & 0,037 & 0,138 & 0,368 & 0,157 & 0,997 \\
11 & 0,009 & 0,232 & 0,028 & 0,102 & 0,338 & 0,118 & 0,827 \\
12 & 0,024 & 0,270 & 0,022 & 0,134 & 0,363 & 0,141 & 0,954 \\
13 & 0,014 & 0,257 & 0,035 & 0,127 & 0,331 & 0,151 & 0,915 \\
14 & 0,012 & 0,246 & 0,032 & 0,110 & 0,313 & 0,135 & 0,848 \\
15 & 0,013 & 0,271 & 0,039 & 0,117 & 0,332 & 0,142 & 0,914 \\
& & & & & & & \\
$\bar{x}$ & 0,013 & 0,292 & 0,032 & 0,138 & 0,353 & 0,160 & 0,987 \\
\hline
\end{tabular}

Tab. 2. Parallelbestimmungen aus Serum mit Homogenisation (mmol/1)

\begin{tabular}{|c|c|c|c|c|c|c|c|}
\hline \multicolumn{2}{|c|}{ Probe $C_{14}$} & \multirow{2}{*}{$\frac{C_{16}}{0,289}$} & \multirow{2}{*}{$\frac{C_{16: 1}}{0,038}$} & \multirow{2}{*}{$\frac{C_{18}}{0,117}$} & \multirow{2}{*}{$\frac{C_{18: 1}}{0,325}$} & \multirow{2}{*}{$\frac{C_{18: 2}}{0,127}$} & \multirow{2}{*}{$\frac{\text { Summe }}{0,901}$} \\
\hline 1 & 0,007 & & & & & & \\
\hline 2 & 0,011 & 0,346 & 0,030 & 0,136 & 0,320 & 0,143 & 0,986 \\
\hline 3 & 0,003 & 0,285 & 0,037 & 0,138 & 0,368 & 0,157 & 0,988 \\
\hline 4 & 0,004 & 0,284 & 0,035 & 0,139 & 0,367 & 0,157 & 0,984 \\
\hline 5 & 0,006 & 0,288 & 0,035 & 0,116 & 0,325 & 0,127 & 0,897 \\
\hline 6 & 0,012 & 0,299 & 0,028 & 0,127 & 0,281 & 0,139 & 0,886 \\
\hline 7 & 0,005 & 0,283 & 0,036 & 0,139 & 0,366 & 0,158 & 0,985 \\
\hline 8 & 0,003 & 0,275 & 0,033 . & 0,120 & 0,342 & 0,142 & 0,915 \\
\hline 9 & 0,003 & 0,265 & 0,033 & 0,122 & 0,337 & 0,142 & 0,902 \\
\hline 10 & 0,011 & 0,298 & 0,031 & 0,127 & 0,280 & 0,140 & 0,887 \\
\hline 11 & 0,003 & 0,291 & 0,030 & 0,138 & 0,352 & 0,160 & 0,973 \\
\hline 12 & 0,013 & 0,300 & 0,029 & 0,128 & 0,281 & 0,139 & 0,890 \\
\hline 13 & 0,008 & 0,253 & 0,029 & 0,102 & 0,306 & 0,118 & 0,827 \\
\hline 14 & 0,013 & 0,422 & 0,035 & 0,170 & 0,375 & 0,172 & 0,187 \\
\hline 15 & 0,004 & 0,291 & 0,028 & 0,140 & 0,352 & 0,160 & 0,978 \\
\hline & 0,007 & 0,298 & 0,032 & 0,131 & 0,332 & 0,145 & 0,945 \\
\hline
\end{tabular}

die Serumproben direkt aus dem über dem Blutkoagulum stehenden Uberstand in verschiedenen Höhen abgenommen wurden, während in der zweiten Reihe die Probennahme nach vorhergehendem Homogenisieren des abgeheberten Serums erfolgte. Wie sich aus den Ergebnissen deutlich zeigt, sind bei der zweiten Untersuchungsreihe aus demselben Serum die im ersten Fall auftretenden „Ausreißer" bis auf zwei verschwunden.

In Abbildung 4 und 5 sind die Chromatogramme eines synthetischen Fettsäurengemisches und einer üblichen Serumanalyse dargestellt.

\section{Untersuchungen zur Veresterungsreaktion}

In Abbildung 6 wird der Reaktionsverlauf der Veresterungsreaktion dargestellt. Wie aus der Abbildung hervorgeht, ist die Reaktion unter den gewählten Bedingungen auch bei 50-facher Konzentration an Fettsäuren nach einer Stunde vollständig.

In Abbildung 7 und 8 werden die Untersuchungen zur Frage der möglichen Umesterungsreaktion mit in Lösung vorhandenen Fettsäureestern dargestellt. Wie aus den Abbildungen hervorgeht, erfolgt bei der Veresterungsreaktion mit Kaliumcarbonat und Alkyljodid keine Umesterung. Auch nach 3-stündiger Behandlung von Trilaurinlösungen konnte im Gaschromatogramm kein Laurinsäuremethylester nachgewiesen werden. Das Problem wurde auch in folgendem Experiment untersucht:

Zunächst wurde von Palmitinsäure nach der neuen Methode ein Methylester dargestellt. In einer zweiten Reaktion wurde unter gleichen Bedingungen durch $\mathrm{Zu}$ gabe von Äthyljodid versucht, aus dem Methylester durch Umesterung einen Äthylester zu erhalten. Auch

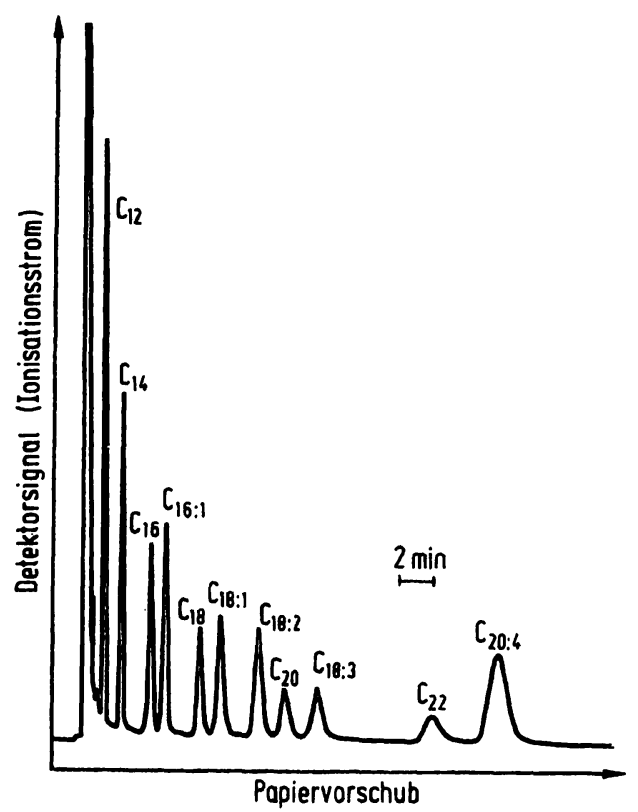

Abb. 4. Gaschromatogramm eines Gemisches von Fettsäuren nach Veresterung. Papiervorschub $0,5 \mathrm{~cm} / \mathrm{min}$ 


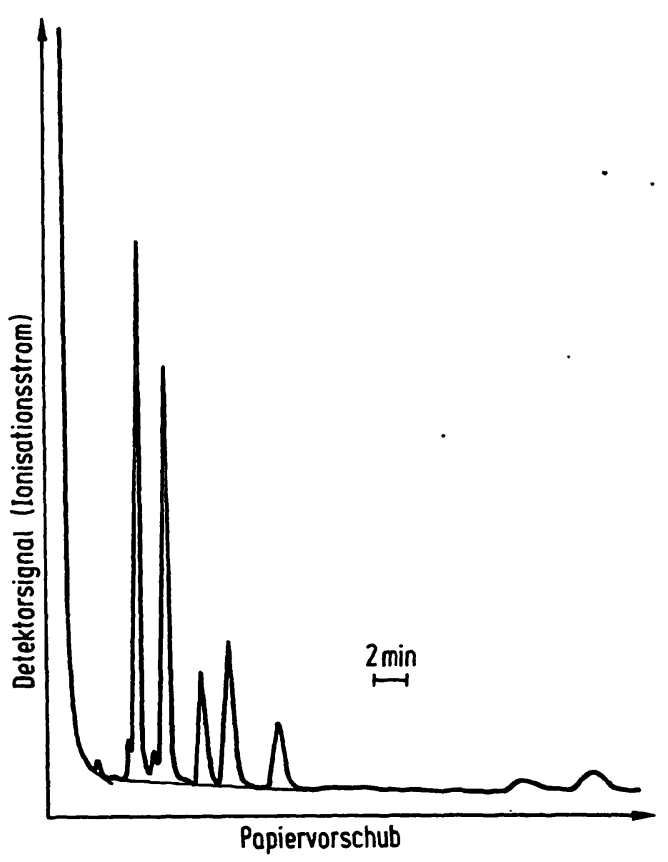

Abb. 5. Gaschromatogramm der unveresterten Fettsäuren im Serum eines polytraumatisierten Patienten. Papiervorschub $0,5 \mathrm{~cm} / \mathrm{min}$.

\begin{tabular}{|c|c|c|c|}
\hline$C: \Delta$ & $\begin{array}{l}\text { Retention } \\
\text { (cm) }\end{array}$ & $\begin{array}{l}\text { Peakhöhe } \\
\text { (cm) }\end{array}$ & $\begin{array}{l}\text { Fettsäure- } \\
\text { konzentration } \\
(\mathrm{mmol} / \mathrm{l})\end{array}$ \\
\hline $12: 0$ & - & - & - \\
\hline $14: 0$ & 1,50 & 0,4 & 0,01 \\
\hline $16: 0$ & 2,65 & 15,60 & 0,53 \\
\hline $17: 0$ & 3,45 & 12,05 & 0,50 \\
\hline $18: 0$ & 4,60 & 3,25 & 0,17 \\
\hline $18: 1$ & 5,45 & 4,15 & 0,27 \\
\hline $18: 2$ & 6,95 & 1,90 & 0,15 \\
\hline $18: 3$ & - & - & - \\
\hline $20: 3$ & 14,30 & 0,3 & 0,05 \\
\hline $20: 4$ & 16,40 & 0,5 & 0,09 \\
\hline $16: 1$ & 3,20 & 0,90 & 0,04 \\
\hline$\overline{\text { Sumn }}$ & $---\cdots$ & - - & $-\overline{131}-\cdots$ \\
\hline
\end{tabular}

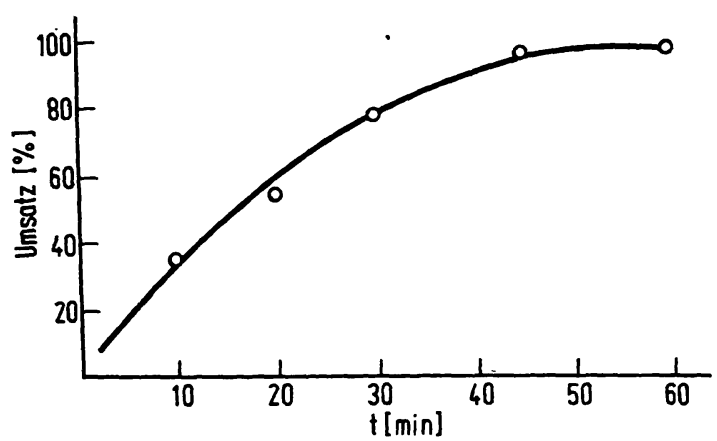

Abb. 6. Reaktionsverlauf der Veresterungsreaktion bei $90^{\circ} \mathrm{C}$ im verschlossenen Reaktionsgefäß

in diesem Fall kann nach Ablauf von 3 Stunden kein Äthylester im Gaschromatogramm nachgewiesen werden, was ohnehin auch nach der Reaktionsgleichung nicht $\mathrm{zu}$ erwarten war.

Experimente zur Frage der Strukturerhaltung, vor allem im Bezug zu Anzahl und Lage von Doppelbindungen bei ungesättigten Fettsäuren

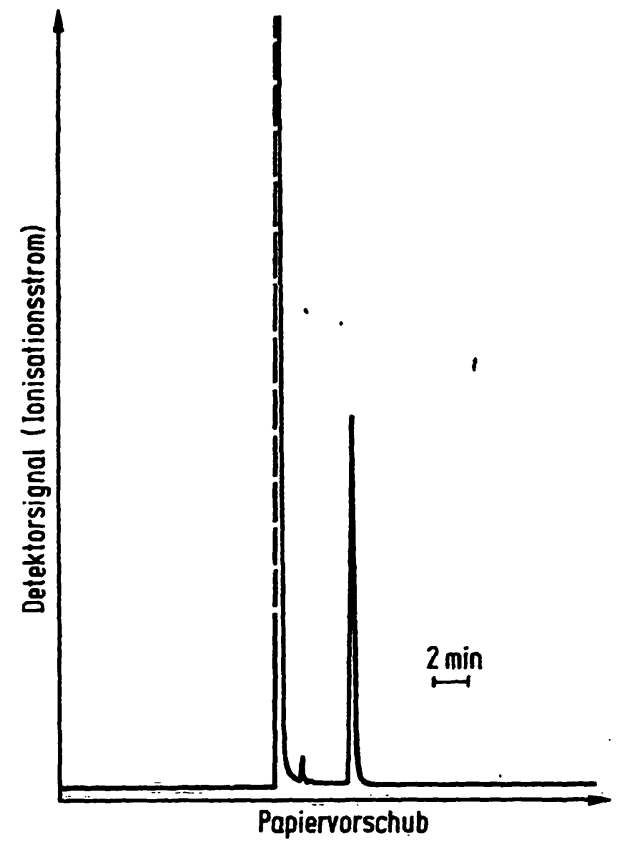

Abb. 7. Gaschromatogramm von Lauryl-Methylester. Papiervorschub $0,5 \mathrm{~cm} / \mathrm{min}$

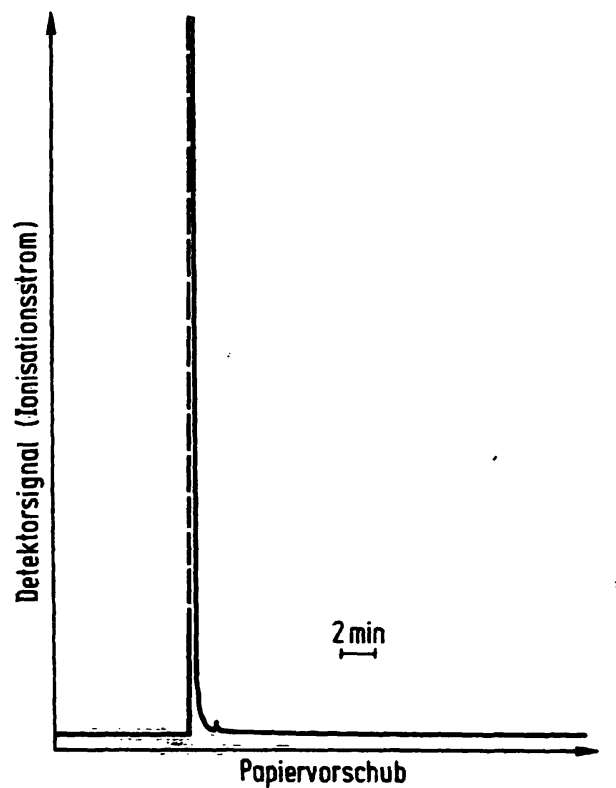

Abb. 8. Gaschromatogramm von Trilaurin nach $3 \mathrm{~h}$ versuchter Umesterung mit $\mathrm{CH}_{3} \mathrm{~J} / \mathrm{K}_{2} \mathrm{CO}_{3}$ aufgenommen unter den gleichen Bedingungen wie bei Abb. 7.

In mehreren Reaktionsansätzen wurden sowohl Linolsäure als auch Linolensäure und Arachidonsäure in getrennten Ansätzen ohne Schutzmaßnahmen (normale Atmosphäre) zu Methylestern umgesetzt. Auch nach 6-stündiger Veresterungszeit traten keine neuen Peaks im Gaschromatogramm auf, was bei einer. Veränderung an einer Doppelbindung z. B. im Sinne einer Sättigung oder bei Seitenreaktionen mit dem Alkyljodid erwartet 
werden muß. Auch die quantitativen Ergebnisse unterscheiden sich dabei nicht von denen nach einer Stunde Veresterung.

\section{Diskussion}

Die hier vorgelegte Fettsäurenbestimmungsmethode verfolgt im wesentlichen zwei Ziele:

1. Die im Gesamtgehalt an Lipiden im Serum vorliegende außerordentlich geringe Konzentration freier Fettsäuren erfordert eine selektive, $d$. h. von den übrigen Lipiden unbeeinflußte Bestimmung in einer Weise, die ohne problematische $Z$ wischentrennungen eine schnelle und weitgehend präzise, analytische Erfassung dieser Lipidfraktion erlaubt.

2. Die Methode sollte so beschaffen sein, daß neben dem Gesamtgehalt eine quantitative Aussage über die einzelnen Fettsäuren möglich ist, wobei im besonderen Maße gewährleistet sein soll, daß gerade die ungesättigten Fettsäuren ohne analytisch bedingte Veränderungen erfaßbar sind. Diese Bedingungen werden in zufriedenstellender Weise durch das vorgelegte Verfahren erfüllt. Zur Beurteilung und Charakterisierung des Verfahrens liegen Erfahrungen an weit über 500 Serumanalysen vor.

Die präzisen, analytischen Daten sind in Tabelle 3 und Tabelle 4 zusammengestellt. Hierbei wurde die Leistungsfähigkeit des Bestimmungsverfahrens zum einen an Serumproben, zum anderen aber auch an synthetischen, organischen Fettsäurelösungen untersucht, bei denen sich naturgemäß schon deshalb präzisere Werte ergaben, weil die problematischsten analytischen Schritte wie

Tab. 3. Analytische Kenndaten bei synthetischen Lösungen

\begin{tabular}{llll}
\hline $\begin{array}{l}\text { Fettsäure } \\
(\mathrm{n}=15)\end{array}$ & $\begin{array}{l}\text { Mittelwert } \\
(\mathrm{mmol} / \mathrm{l})\end{array}$ & $\begin{array}{l}\text { Standard- } \\
\text { Abweichung } \\
(\mathrm{mmol} / \mathrm{l})\end{array}$ & $\begin{array}{l}\text { Variations- } \\
\text { koeffizient } \\
(\%)\end{array}$ \\
\hline $\mathrm{C}_{16: 0}$ & 0,274 & 0,016 & 5,8 \\
$\mathrm{C}_{18: 0}$ & 0,128 & 0,007 & 5,5 \\
$\mathrm{C}_{18: 1}$ & 0,343 & 0,015 & 4,4 \\
$\mathrm{C}_{18: 2}$ & 0,148 & 0,008 & 5,4 \\
$\begin{array}{l}\text { Summe der } \\
\text { unveresterten }\end{array}$ & & & \\
Fettsäuren & 0,939 & 0,045 & 4,8 \\
\hline
\end{tabular}

Tab. 4. Analytische Kenndaten bei Serumproben

\begin{tabular}{llll}
\hline $\begin{array}{l}\text { Fettsäure } \\
(n=15)\end{array}$ & $\begin{array}{l}\text { Mittelwert } \\
(\mathrm{mmol} / \mathrm{l})\end{array}$ & $\begin{array}{l}\text { Standard- } \\
\text { Abweichung } \\
(\mathrm{mmol} / \mathrm{l})\end{array}$ & $\begin{array}{l}\text { Variations- } \\
\text { koeffizient } \\
(\%)\end{array}$ \\
\hline $\mathrm{C}_{16: 0}$ & 0,300 & 0,04 & 13,27 \\
$\mathrm{C}_{18: 0}$ & 0,131 & 0,02 & 11,8 \\
$\mathrm{C}_{18: 1}$ & 0,332 & 0,03 & 9,95 \\
Mischung & 0,945 & 0,08 & 8,85 \\
\hline
\end{tabular}

Probennahme, Extraktions- und Ǔberführungsschritte sich nicht in so negativer Weise bemerkbar machen konnten, wie das bei Serumproben mit an Protein gebundenen Fettsäuren der Fall ist.

Hervorgehoben werden sollen die Punkte, die das Verfahren charakterisieren und die für die Analytik der unveresterten Fettsäuren vor allem bezüglich ihres Stellenwertes in der Diagnostik und der Beurteilung von allgemeinen Stoff wechselsituationen entscheidend sind.

Grundlegende Bedeutung für eine Aussage kommt der analytischen Qualität des Verfahrens zu. Die interessierenden Substanzen werden direkt gemessen, wobei sichergestellt ist, daß sie nicht durch den Analysenablauf z. B. durch Seitenreaktionen oder unerwünschte Vorgänge verfälscht werden: Es werden einerseits keine Strukturveränderungen im Sinne von Sättigungsoder Oxidationsvorgängen beobachtet und andererseits durch Vermeidung von Umesterungsreaktionen zusätzliche quantitative Verschiebungen der Zusammensetzung verhindert.

Die ungesättigten Fettsäuren liegen im Serum in so niedriger Konzentration im Vergleich zu den übrigen Lipiden vor, daß sie bei einer Bestimmung innerhalb einer Gesamt-Fettsäurenbestimmung (meist durchgeführt über eine Umesterung aller im Lipidextrakt vorhandener Fettsäuren) nicht erfaßbar sind. D. h. selbst erhebliche Änderungen in dieser Fraktion: können wegen des verschwindend kleinen Anteils von durchschnittlich weniger als $0,1 \%$ der Gesamtlipide nicht erkannt werden.

Die selektive und quantitative Erfassung der ungesättigten Fettsäuren selbst ist erforderlich, wenn Aussagen über diese Fraktion und die durch sie repräsentierte endogene Versorgung gemacht werden sollen. In diesem Zusammenhang ist darauf hinzuweisen, wie gering - von den prinzipiellen methodischen Problemen wie z. B. der Detergenzwirkung von Schwermetallseifen bei photometrischen Verfahren einmal ganz abgesehen der Aussagewert der Bestimmung des Gesamtfettsäurengehaltes ist. Allein der enorme und unkontrollierbare Einfluß, den die psychische Situation des Probanden bei der Probennahme auf den Gesamtgehalt der ungesättigten Fettsäuren ausübt (25), macht es sehr schwierig, einen Normalwert zu ermitteln.

Abgesehen von dieser Problematik kann durch das sehr empfindliche und leistungsfähige Analysenverfahren - wie in Tabelle 1 und 2 dargestellt - deutlich gezeigt werden, welche Bedeutung der Art der Probenvorbereitung gerade bei eiweißgebundenen Stoffen niedriger Konzentration hinsichtlich der Qualität des Analysenergebnisses zukommt. Es ist an dieser Stelle mit allem Nachdruck daraufhin zu weisen, daß ein analytisches Verfahren, welches die Problematik der Probennahme und die Interpretation des Analysenergebnisses im Bezug zur Probenqualität außer Acht läßt, für die praktische Anwendung wertlos ist. 


\section{Literatur}

1. Szent-Györgyi, A. von \& Tominaga, T. (1924), Biochem. Z. $146,226-238$.

2. Hirtz, J., Berret, R. \& Rio, B. (1969), Chim. Anal. (Paris) $51,434-439$.

3. Stewart, C. P. \& White, A. C. (1929), Biochem. J. 23,2, 1263-1266.

4. Davis, B. D. (1947), Arch. Biochem. 15, 351.

5. Dole, V. P. (1956), J. Clin. Invest. 35, 150-154.

6. Dole, V. P. \& Meinertz, H. (1960), J. biol. Chem. 235, 2595-2599.

7. Gordon, R. S. (1960), Amer. J. Clin. Nutr. 8, 740.

8. Trout, D. L., Estes, E. H. \& Friedberg, S. J. (1960), J. Lipid Res. 1, 199-202.

9. Ayers, C. W. (1956), Anal. Chim. Acta 15, 77-83.

10. Iwayama, Y. (1959), J. Pharm. Soc. Japan 79, 552.

11. Duncombe, W. G. (1964), Clin. Chim. Acta 9, 122.

12. Itaya, K. \& Ui, M. (1965), J. Lipid Res. 6, 16.

13. Novák, M. (1965), J. Lipid Res. 6, 431-433.

14. Laurell, S. \& Tibbling, G. (1967), Clin. Chim. Acta 16, $57-62$.
15. James, A. T. \& Martin, A. J. P. (1952), Biochem. J. 50, 679-690.

16. McKeown, G. G. \& Read, S. İ. (1965), Anal. Chem. 37, 1780-1781.

17. Rumsey, T. S., Noller, C. H., Burns, J. C., Kalb, D.; Rhykerd, C. L. \& Hill, D. L. (1964), Dairy Sci. 47, 1418.

18. Luddy, F. E., Barford; R. A. \& Riemenschneider, R. W. (1960), J. Amer. Oil Chemists' Soc. 37, 447-459.

19. Metcalfe, L. D. \& Schmitz, A. A. (1961), Anal. Chem. 33, $363-364$.

20. Schlenk, H. \& Gellerman, J. L. (1960), Anal. Chem. 32, $1412-1414$.

21. Thenot, J. P., Horning, E. C. Stafford, M. \& Horning, M. C. (1972), Anal. Letters 5, 217-223.

22. Claisen, L. (1894), Ber. Deut. Chem. Ges. 27, 3182-3184.

23. Kawahara, F. K. (1968), Anal. Chem. 40, 1009-1010.

24. Grünert, A. \& Bäßler, K. H. (1973), Z. Analyt. Chem. 267, 342-346.

25. Gordon, R. S. jr. \& Cardon, P., zitiert nach: Fredrickson, D. S. \& Gordon, R. S. jr. (1958), Physiol. Rev. 38, 585-630.

Dr. rer. nat. Dr. med. A. Grünert Institut fur Physiologische Chemie II 65 Mainz

Langenbeckstraße 1 